\title{
Associations among osteocalcin, leptin and metabolic health in children ages 9-13 years in the United States
}

\author{
Kelly Virecoulon Giudici ${ }^{1}$, Joseph M. Kindler², Berdine R. Martin ${ }^{3}$, Emma M. Laing ${ }^{2}$, George P. McCabe ${ }^{4}$, \\ Linda D. McCabe3, Dorothy B. Hausman², Lígia Araújo Martini', Richard D. Lewis², Connie M. Weaver ${ }^{3}$, \\ Munro Peacock ${ }^{5}$ and Kathleen M. Hill Gallant ${ }^{3^{*}}$
}

\begin{abstract}
Background: This study aimed to investigate the relationships among osteocalcin, leptin and metabolic health outcomes in children ages 9-13 years.

Methods: This was a cross-sectional analysis of baseline data from 161 boys and 157 girls (ages 9-13 years) who previously participated in a double-blinded randomized placebo controlled trial of vitamin D supplementation. Relationships among fasting serum total osteocalcin (tOC), undercarboxylated osteocalcin (UCOC), leptin, and metabolic health outcomes were analyzed.
\end{abstract}

Results: Approximately 52\% of study participants were obese based on percent body fat cutoffs ( $>25 \%$ for boys and $>32 \%$ for girls) and about $5 \%$ had fasting serum glucose within the prediabetic range (i.e. 100 to $125 \mathrm{mg} / \mathrm{dL}$ ). Serum tOC was not correlated with leptin, glucose, insulin, HOMA-IR, or HOMA- $\beta$ after adjusting for percent body fat. However, serum uCOC negatively correlated with leptin (partial $r=-0.16 ; p=0.04$ ) and glucose (partial $r=-0.16 ; p=0.04$ ) after adjustment for percent body fat. Leptin was a positive predictor of insulin, glucose, HOMA-IR, and HOMA- $\beta$ after adjusting for age, sex and percent body fat (all $p<0.001$ ).

Conclusions: These data depict an inverse relationship between leptin and various metabolic health outcomes in children. However, the notion that tOC or ucOC link fat with energy metabolism in healthy children was not supported.

Clinical trial registration number: NCT00931580.

Keywords: Osteocalcin, Children, Leptin, Obesity, Glucose, Insulin

\section{Background}

The relationships between bone, adiposity and energy metabolism have been of recent interest [1-7]. Whereas excess adiposity may benefit bone development as a result of earlier and prolonged maturation [8], some studies have identified fat mass as a negative determinant of skeletal endpoints after adjusting for pertinent confounders $[8,9]$. One explanation for a potentially adverse influence of adiposity on bone involves obesity-related metabolic health outcomes, specifically insulin resistance [10]. This is of particular importance considering that obese children

\footnotetext{
* Correspondence: hillgallant@purdue.edu

${ }^{3}$ Department of Nutrition Science, Purdue University, 700 W. State Street,

West Lafayette, IN 47907, USA

Full list of author information is available at the end of the article
}

are overrepresented in pediatric skeletal fracture cases [11], and that certain bone-derived factors are understood to contribute to energy metabolism [12]. Therefore, elucidating the mechanisms by which adiposity influences bone, as well as how bone-derived factors influence the fat-bone relationship and metabolic health, warrants further investigation.

Leptin is a hormone that has received considerable attention in relation to the fat-bone connection, despite its better-known role in appetite regulation [1]. Leptin has been shown to influence bone through numerous mechanisms [1], thus it is not surprising that the role of leptin on bone is both complex and controversial [13]. Ducy et al. [1] identified leptin as a potent inhibitor of bone formation acting through a central nervous system 
mechanism. In mice, intracerebroventricular leptin infusion stimulated hypothalamic leptin receptor (LEPR) expression, promoting norepinephrine release, and in turn, activating osteoblast $\beta 2$-adrenergic receptors. Ultimately, this resulted in altered bone metabolism in favor of bone resorption [1, 14]. Conversely, peripheral leptin signaling through LEPR in bone marrow stromal cells promoted differentiation to the osteoblastic lineage over the adipocytic lineage [15]. Further, LEPR signaling in osteoblasts increased osteoprotegerin (OPG) and decreased the receptor activator of nuclear factor $\mathrm{\kappa B}$ ligand (RANKL), resulting in decreased osteoclastogenesis. Thus, in contrast to the bone-resorptive effects of leptin via the central nervous system, peripheral leptin signaling at the level of the skeleton appears to favor bone formation [13].

The bone-derived osteocalcin, a protein produced by osteoblasts, is also suspected to play an integral role in the link between fat, bone, and metabolic health $[16,17]$. However, there is still considerable debate surrounding the role of osteocalcin, including its sub-fractions (i.e., carboxylated $[\mathrm{cOC}]$ and undercarboxylated $[\mathrm{ucOC}]$ ), in the complex fat-bone connection. This is especially true for pediatric populations. Osteocalcin-null mice versus wild-type littermates have greater visceral fat, and consequently, present with hyperglycemia and are insulin resistant [3]. In humans, there is conflicting evidence for a relationship between tOC and glucose metabolism with some reports showing no relationship $[18,19]$, and others showing an inverse relationship between tOC and glucose concentrations [20-22]. In contrast, ucOC seems to play a role in pancreatic $\beta$ cell proliferation and insulin secretion, as well as improving peripheral insulin sensitivity through the regulation of the adipokine adiponectin $[3,4]$. Whereas experimental $[3,4]$ studies have suggested that ucOC might play a more pivotal role in energy homeostasis than $\mathrm{tOC}$, obese versus normal weight children have lower tOC, which is a negative predictor of serum leptin and insulin resistance [23], thus the relative importance of tOC and ucOC on metabolic health is not currently well defined. Additionally, the effects of physical activity through skeletal loading on the bone-fatenergy metabolism relationship have been described, with ucOC proposed as an endocrine mediator communicating the energy needs of bone during physical activity $[7,24,25]$.

The objective of this study was to examine relationships among serum osteocalcin (tOC and ucOC) and leptin with metabolic health outcomes in a large cohort of boys and girls who were at the early stages of maturation. We hypothesized that leptin and osteocalcin would be negatively related to one another, and that leptin would be a negative predictor of serum glucose, insulin and insulin resistance. In addition, we hypothesized that $\mathrm{ucOC}$ would be a consistent positive predictor of the various metabolic health outcomes.

\section{Methods \\ Study design and population}

This study is a cross sectional ancillary analysis of baseline data from a previously conducted double blinded placebo-controlled vitamin D supplementation trial [26] which included 318 boys and girls ages 8 to 13 years living in the United States (i.e., The GAPI Trial - University of Georgia [UGA], Purdue University [PU] and Indiana University [IU]). All study participants were healthy and absent of any chronic diseases, as determined by self- and parental report. Inclusion criteria included black and white non-Hispanic girls and boys, and sexual maturity stage 2 and 3, which was self-assessed as previously described [26]. Exclusion criteria included menarche in girls, growth disorders, or any disease, medication, or condition known to influence bone metabolism. The GAPI study was approved by the Institutional Review Boards for Human Subjects at Purdue University, the University of Georgia, and Indiana University School of Medicine. All participants and their parents or legal guardians provided informed assent and consent, respectively.

\section{Study variables}

Blood samples were collected after 12-h fasting for the biochemical analyses of serum glucose, insulin, tOC, ucOC and leptin. Serum was stored at $-80{ }^{\circ} \mathrm{C}$ until analysis. Each analyte was measured at a single laboratory for all participants.

Serum tOC and ucOC were measured in duplicate by enzyme-linked immunosorbent assay (ELISA; tOC: MicroVue $^{\text {tw }}$, Quidel Corp., San Diego, CA; ucOC: Takara Bio, Inc., Japan). Intra- and interassay $\mathrm{CVs}$ for tOC were 4.8-9.8 and 4.8-10.0\%, respectively; Mean intra- and interassay $\mathrm{CVs}$ for ucOC were 5.2 and $8.3 \%$, respectively. Serum ucOC measurements were only available for 170 subjects. Serum leptin and insulin were measured in duplicate by radioimmunoassay (RIA; EMD Milipore, Billerica, MA). Mean intra- and interassay CVs for insulin were 3.5 and $5.3 \%$, respectively; and 5.0 and $4.5 \%$ for leptin, respectively. Serum glucose was measured in triplicate by microtiter modification of the enzymatic Autokit Glucose method (Wako Chemicals USA, Richmond, VA). The mean intra- and interassay CVs were 1.8 and $2.2 \%$, respectively. The Homeostasis Model of Assessment Estimate of Insulin Resistance (HOMA-IR) was calculated as: fasting glucose $(\mathrm{mg} / \mathrm{dL}) \mathrm{x}$ fasting insulin $(\mu \mathrm{U} / \mathrm{mL}) / 405$. The Homeostatic Model of Assessment Estimate of $\beta$ Cell Function (HOMA- $\beta$ ) was calculated as: $[360 \mathrm{x}$ fasting insulin $(\mu \mathrm{U} / \mathrm{mL})] /[$ fasting glucose $(\mathrm{mg} / \mathrm{dL})-63]$. Height and weight were measured and BMI-for-age percentiles were calculated from the 
2000 CDC Growth Charts [27], and obese status was defined according to percent body fat cutoffs ( $>25$ for boys and $>32 \%$ for girls) $[9,28,29]$.

Percent body fat was assessed using dual-energy X-ray absorptiometry (DXA; Delphi-A, Hologic Inc [UGA]; Lunar iDXA, GE Medical Instruments [PU]; and Hologic Discovery-W [IU]). The same technician at each site conducted scans and performed analyses using instrument-specific software and protocols. Detailed procedures are described previously [26].

\section{Statistical analysis}

Descriptive statistics were used for characterization of the study subjects. The normality of the distribution of each variable was assessed using the Shapiro-Wilk test, and variables were analyzed after logarithmic transformation. Means for quantitative variables were compared by Student's t-tests or analysis of variance (ANOVA). Pearson correlations, partial correlations and linear regression analyses were used to determine relationships among variables with adjustments for potential confounding variables. Percent body fat was included as a covariate while examining the relationships between leptin, osteocalcin, and metabolic health outcomes. Partial correlations adjusted for percent body fat or BMI yielded similar results. Sample size for individual analyses varied according to data availability for each variable, and are described in the tables. Statistical analyses were performed using the Statistical Analysis Software, version
9.4 (Cary, NC). Statistical significance for all analyses was set at $\alpha=0.05$.

\section{Results}

\section{Anthropometrics and biochemistry}

Descriptive participant characteristics are presented in Table 1. The percentage of participants in sexual maturation stages 2 and 3 were $65 \%$ and 35\%, respectively. Girls compared with boys were younger, shorter, and had higher percent body fat, serum leptin, and HOMA- $\beta$ (all $p<0.001$ ). Blacks compared with whites were younger, had higher BMI-for-age percentile, higher serum leptin, higher HOMA- $\beta$ and higher serum tOC, but lower serum ucOC (all $p<0.050$ ). Black females presented higher serum insulin concentrations and higher HOMA-IR, when compared with all other race by sex subgroups (both $p<0.050$; Table 1 ).

Fifteen of the 318 total subjects (4.7\%) had fasting serum glucose concentrations within the pre-diabetic range $(\geq 100<125 \mathrm{mg} / \mathrm{dL})$, with $110 \mathrm{mg} / \mathrm{dL}$ being the highest observed value. Based on percent body fat cutoffs [9, 28, 29], 51.8\% $(n=156)$ of participants were classified as obese. Compared with the non-obese subjects, obese individuals had higher serum leptin, insulin, HOMA-IR and HOMA- $\beta$ (all $p<0.0001$ ), and lower tOC $(p=0.0002)$ (Table 2). However, ucOC concentrations did not differ between non-obese and obese groups.

Table 1 Anthropometric and biochemical characterization of the population according to sex and race

\begin{tabular}{|c|c|c|c|c|c|c|c|c|c|}
\hline & \multicolumn{2}{|c|}{ Total } & \multirow{3}{*}{$\begin{array}{l}\text { Black male } \\
(n=82) \\
\text { Mean (SEM) }\end{array}$} & \multirow{3}{*}{ 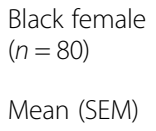 } & \multirow{3}{*}{$\begin{array}{l}\text { White male } \\
(n=79) \\
\text { Mean (SEM) }\end{array}$} & \multirow{3}{*}{$\begin{array}{l}\text { White female } \\
(n=77) \\
\text { Mean (SEM) }\end{array}$} & \multicolumn{3}{|l|}{ Effects } \\
\hline & & & & & & & \multirow{2}{*}{$\begin{array}{l}\text { Sex } \\
p \text {-value }\end{array}$} & \multirow{2}{*}{$\begin{array}{l}\text { Race } \\
p \text {-value }\end{array}$} & \multirow{2}{*}{$\begin{array}{l}\text { Sex } \times \text { race } \\
p \text {-value }\end{array}$} \\
\hline & $n$ & Mean (SEM) & & & & & & & \\
\hline Age (years) & 318 & $11.4(0.1)$ & $11.8(0.1)$ & $10.5(0.1)$ & $12.1(0.1)$ & $11.0(0.1)$ & $<0.0001$ & 0.0006 & 0.5396 \\
\hline \multicolumn{10}{|l|}{ Anthropometry } \\
\hline Weight (kg) & 318 & $47.5(0.7)$ & $49.4(1.4)$ & $48.0(1.3)$ & $48.0(1.5)$ & $44.4(1.1)$ & 0.1181 & 0.0647 & 0.5113 \\
\hline Height (m) & 318 & $1.51(0.01)$ & $1.52(0.01)$ & $1.48(0.01)$ & $1.54(0.01)$ & $1.49(0.01)$ & $<0.0001$ & 0.1555 & 0.7783 \\
\hline BMI-for-age (percentile) & 318 & $68.3(1.6)$ & $72.1(2.9)$ & $77.6(3.1)$ & $56.9(3.6)$ & $66.5(3.1)$ & 0.1036 & 0.0013 & 0.3239 \\
\hline Body fat (\%) & 301 & $29.9(0.6)$ & $25.5(1.0)$ & $33.2(0.9)$ & $28.3(1.1)$ & $33.3(1.0)$ & $<0.0001$ & 0.1386 & 0.1832 \\
\hline \multicolumn{10}{|l|}{ Biochemistry } \\
\hline Leptin (ng/mL) & 305 & $11.1(0.6)$ & $8.1(0.9)$ & $16.0(1.2)$ & $8.7(1.2)$ & $11.6(0.9)$ & $<0.0001$ & 0.0269 & 0.4041 \\
\hline $\mathrm{ucOC}(\mathrm{ng} / \mathrm{mL})$ & 170 & $30.6(1.4)$ & $20.3(2.4)$ & $27.6(2.6)$ & $39.8(1.7)$ & $41.8(3.1)$ & 0.1415 & $<0.0001$ & 0.1805 \\
\hline Total osteocalcin (ng/mL) & 303 & $33.3(0.7)$ & $38.5(1.5)$ & $35.5(1.6)$ & $29.8(0.9)$ & $29.5(0.8)$ & 0.1457 & $<0.0001$ & 0.2302 \\
\hline Glucose (mg/dL) & 317 & $89.0(0.4)$ & $89.4(0.8)$ & $89.4(0.8)$ & $89.1(0.8)$ & $87.9(0.8)$ & 0.4352 & 0.2441 & 0.4378 \\
\hline Insulin ( $\mu \mathrm{U} / \mathrm{mL})$ & 318 & $20.3(0.6)$ & $18.9(0.8)$ & $25.9(1.5)$ & $18.1(1.4)$ & $18.0(0.9)$ & 0.0006 & $<0.0001$ & 0.0236 \\
\hline HOMA- $\beta$ & 317 & 307.3 (13.9) & 301.5 (31.8) & 389.4 (36.6) & $263.4(20.7)$ & $274.2(13.2)$ & 0.0007 & 0.0015 & 0.1704 \\
\hline HOMA-IR & 317 & $4.5(0.1)$ & $4.2(0.2)$ & $5.7(0.3)$ & $4.0(0.3)$ & $4.0(0.2)$ & 0.0020 & $<0.0001$ & 0.0257 \\
\hline
\end{tabular}

Standard Error of the Mean; Body mass index; Undercarboxylated osteocalcin; Homeaostasis Model of Assessment Estimate of $\beta$ Cell Function; Homeaostasis Model of Assessment Estimate of Insulin Resistance; Results of two-way ANOVA for sex, race and sex x race interactions investigated. All variables were analyzed after logarithmic transformation

The values that are italic are $p$-values indicating significance 
Table 2 Biochemical characterization of the population according to nutrition status defined by percent body fat cutoffs [9, 28, 29]

\begin{tabular}{lllll}
\hline & & Non-obese $(n=145)$ & Obese $(n=156)$ & $p$ Mean (SEM) \\
\hline Leptin $(\mathrm{ng} / \mathrm{mL})$ & $n$ & Mean $($ SEM) & $16.9(0.8)$ & $<0.0001$ \\
ucOC $(\mathrm{ng} / \mathrm{mL})$ & 288 & $5.1(0.3)$ & $30.8(1.9)$ & 0.8644 \\
Total osteocalcin $(\mathrm{ng} / \mathrm{mL})$ & 167 & $30.6(2.1)$ & $31.3(0.8)$ & 0.0002 \\
Glucose $(\mathrm{mg} / \mathrm{dL})$ & 286 & $36.2(1.1)$ & $89.5(0.5)$ & 0.3608 \\
Insulin $(\mu \mathrm{U} / \mathrm{mL})$ & 300 & $88.8(0.6)$ & $23.6(1.0)$ & $<0.0001$ \\
HOMA- $\beta$ & 301 & $17.1(0.6)$ & $355.8(25.7)$ & $<0.0001$ \\
HOMA-IR & 300 & $256.2(10.8)$ & $5.2(0.2)$ & $<0.0001$ \\
\hline
\end{tabular}

Standard Error of the Mean; Body mass index; Undercarboxylated osteocalcin; Homeostasis Model of Assessment Estimate of $\beta$ Cell Function; Homeostasis Model of Assessment Estimate of Insulin Resistance. Results of Student's $T$-test. All variables were analyzed after logarithmic transformation

The values that are italic are $p$-values indicating significance

\section{Correlations with tOC and uCOC}

In the unadjusted analyses, tOC was weakly negatively correlated with leptin and weakly positively correlated with height, but not correlated with any other anthropometric or biochemical outcomes (Table 3). After adjusting for percent body fat, tOC did not correlate with any of our biochemical outcomes, height or weight. Only after adjusting for percent body fat, ucOC was weakly negatively correlated with leptin and glucose. As depicted in Fig. 1, leptin remained positively, albeit weakly, associated with ucOC after adjusting for age, sex, and percent body fat.

\section{Correlations with leptin}

Leptin was strongly positively correlated with percent body fat $(\mathrm{r}=0.878, p<0.0001)$ and modestly positively correlated with BMI-for-age percentile $(\mathrm{r}=0.596$, $p<0.0001)$. After adjusting for age, sex, and percent body fat, leptin was a positive predictor of serum glucose (partial $\mathrm{r}=0.20, p=0.001, \beta=0.4229$ ), serum insulin (partial $\mathrm{r}=$ $0.47, p<0.0001, \beta=0.9245$ ), HOMA- $\beta$ (partial $\mathrm{r}=0.29$, $p<0.0001, \beta=0.5805$ ), and HOMA-IR (partial $\mathrm{r}=0.48$, $p<0.0001, \beta=0.9481$ ), although the strength of these associations were weak to moderate (Fig. 2).

\section{Discussion}

Recent findings have identified new potential metabolic interactions between the skeleton, fat tissue, and energy metabolism. Whereas insulin is involved in skeletal development via the bone-forming osteoblasts [30], Karsenty \& Ferron [31] have suggested that insulin, bone resorption, and osteocalcin activity are regulated by a feed forward loop, in which insulin signaling in osteoblasts decreases the expression of the gene that encodes the osteoprotegerin $(\mathrm{Opg})$, thus increasing osteoclastmediated bone resorption which occurs at a $\mathrm{pH}$ of 4.5. This acidic $\mathrm{pH}$ favors the decarboxylation of osteocalcin, releasing ucOC into the systemic circulation. Thereafter, ucOC plays a regulatory role in glucose metabolism by promoting pancreatic insulin secretion [32] and peripheral insulin sensitivity $[3,4,12]$. Furthermore, leptin has been shown to modulate insulin sensitivity by reducing osteocalcin bioactivity in osteoblasts [2]. Limited clinical

Table 3 Unadjusted correlation and partial correlation adjusted for percent body fat of total osteocalcin and undercarboxylated osteocalcin with biochemical variables

\begin{tabular}{|c|c|c|c|c|c|c|c|c|c|c|c|c|}
\hline & \multicolumn{6}{|c|}{ Total osteocalcin } & \multicolumn{6}{|c|}{ Undercarboxylated osteocalcin } \\
\hline & \multicolumn{3}{|c|}{ Unadjusted } & \multicolumn{3}{|c|}{ Adjusted for percent body fat } & \multicolumn{3}{|c|}{ Unadjusted } & \multicolumn{3}{|c|}{ Adjusted for percent body fat } \\
\hline & $n$ & $r$ & $p$ & $n$ & $r$ & $p$ & $n$ & $r$ & $p$ & $n$ & $r$ & $p$ \\
\hline Leptin & 303 & -0.169 & 0.0031 & 286 & 0.041 & 0.4861 & 170 & -0.037 & 0.6285 & 167 & -0.162 & 0.0368 \\
\hline Insulin & 303 & 0.001 & 0.9864 & 286 & 0.096 & 0.1057 & 170 & -0.048 & 0.5345 & 167 & -0.076 & 0.3282 \\
\hline Glucose & 302 & -0.026 & 0.6495 & 285 & -0.033 & 0.5793 & 169 & -0.150 & 0.0511 & 166 & -0.159 & 0.0420 \\
\hline HOMA-IR & 302 & -0.006 & 0.9149 & 285 & 0.082 & 0.1666 & 169 & -0.066 & 0.3965 & 166 & -0.096 & 0.2185 \\
\hline HOMA- $\beta$ & 302 & 0.007 & 0.9060 & 285 & 0.096 & 0.1076 & 169 & 0.049 & 0.5229 & 166 & 0.036 & 0.6488 \\
\hline Weight & 303 & -0.008 & 0.8904 & 286 & 0.097 & 0.1028 & 170 & -0.056 & 0.4672 & 167 & -0.102 & 0.1923 \\
\hline Height & 303 & 0.135 & 0.0183 & 286 & 0.101 & 0.0901 & 170 & 0.033 & 0.6641 & 167 & 0.035 & 0.6589 \\
\hline
\end{tabular}

Homeostasis Model of Assessment Estimate of Insulin Resistance; Homeostasis Model of Assessment Estimate of $\beta$ Cell Function; All variables were analyzed after logarithmic transformation

The values that are italic are $p$-values indicating significance 

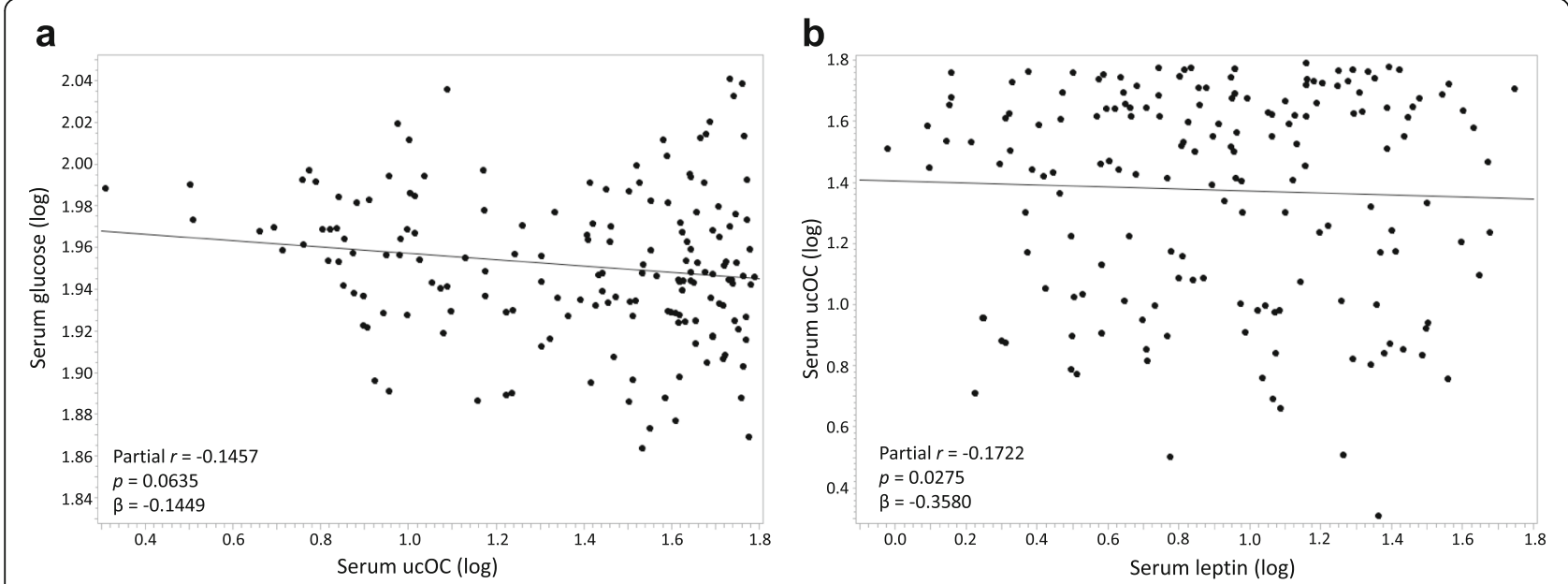

Fig. 1 Partial regression plots between ucOC and (a) glucose and (b) leptin adjusted for age, sex and percent body fat in children living in the United States
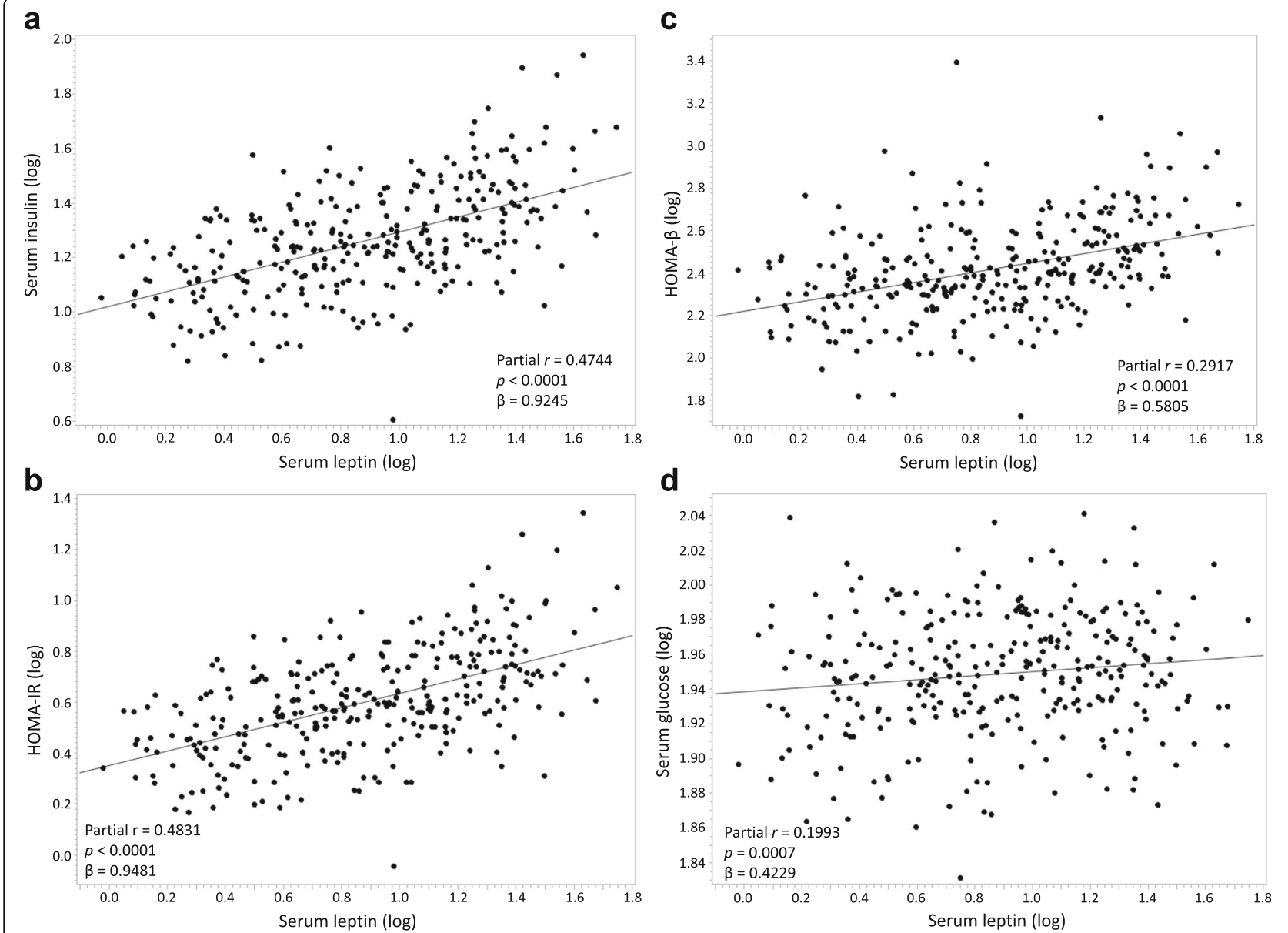

Fig. 2 Partial regression plots between leptin and (a) serum insulin, (b) HOMA-IR, (c) HOMA- $\beta$, and (d) serum glucose adjusted for age, sex and percent body fat among children living in the United States 
studies have investigated the relationships between fat- and bone-derived hormonal mediators and energy metabolism [12, 18, 24, 33], and data in youth are sparse. Therefore, the primary aim of this study was to examine the relationships between osteocalcin and leptin with various metabolic health outcomes in a large cohort of early adolescent boys and girls living in the United States. Despite a weak negative correlation between leptin and ucOC, we did not find a relation between osteocalcin and insulin resistance or other metabolic health outcomes. This finding corroborates with the results from Abseyi et al. [18], in which 150 obese non-diabetic children and adolescents were evaluated and no relationship between osteocalcin and insulin resistance was found, however only tOC was assessed in that study. Another study of 248 young Finnish women also found no correlations among osteocalcin (tOC, cOC, or ucOC), glucose, insulin, and HOMA-IR [19].

Corroborating the conclusions of various other studies, data from the current study do not support the notion that osteocalcin plays a role in glucose metabolism in our cohort of children living in the United States. One key characteristic of our study participants is that they were recruited to be generally healthy and absent of any chronic disease, including prediabetes or type 2 diabetes. This is an important consideration given that the role of osteocalcin in energy metabolism may be dependent upon the presence of chronic disease. We found, however, an obesity-related difference in tOC. Takaya et al. [33] observed that adolescents with type 2 diabetes had lower ucOC levels than normal weight controls, while no difference was found between non-diabetic obese subjects and controls. In addition, differences in tOC were not observed. Another study has shown that, in overweight children only, tOC and $\mathrm{COC}$ were significant negative predictors of long-term glucose control (i.e., HbA1C) [34]. Further, it is possible that osteocalcin may play a larger role in individuals with obesity-related chronic diseases such as prediabetes or type 2 diabetes. Other studies considering individuals with obesity-related chronic diseases showed similar results such that Rosato et al. [35] reported that diabetic adults had $71 \%$ lower tOC concentrations than healthy controls. Improved glycemic control after a 2-month intervention (therapy with insulin or oral medication) among diabetic subjects was associated with an increase in tOC concentrations. In addition, change in tOC was a negative predictor of fasting serum glucose concentrations in these same study participants. Meanwhile, no significant correlations were found between $\mathrm{tOC}$ and fasting glucose for the healthy control group. Okazaki et al. [36] also observed an increase in tOC after therapy in poorly controlled noninsulin-dependent patients.
In addition to the relatively small number of studies that have evaluated ucOC in relation to energy metabolism among adolescents, it is difficult to compare across studies because the range of values for ucOC depends on the assay employed. Applying the same method of analysis used in our study (i.e., ELISA), Van Summeren et al. [37] found mean ucOC concentrations of $31.3 \mathrm{ng} / \mathrm{mL}$ among 86 children and adolescents from 3 to 18 years of age from the Netherlands. Rochefort et al. [38] observed mean ucOC of $34.5 \mathrm{ng} / \mathrm{mL}$ among 13 nonobese children and $34.3 \mathrm{ng} / \mathrm{mL}$ among 27 obese children aged 9 to 12 years old. Using RIA, Pollock et al. [12] found mean ucOC of $5.6 \mathrm{ng} / \mathrm{mL}$ among normal glucose subjects and $7.8 \mathrm{ng} / \mathrm{mL}$ among subjects with prediabetes in a group of U.S. overweight children from 7 to 11 years old. Tubic et al. [34], in a study with 108 Swedish 2-9 year old children, found mean tOC and ucOC of $82.6 \mathrm{ng} / \mathrm{mL}$ and $7.0 \mathrm{ng} / \mathrm{mL}$, respectively, among normal weight subjects and mean of $77.0 \mathrm{ng} / \mathrm{mL}$ and $7.9 \mathrm{ng} / \mathrm{mL}$ among overweight subjects, however differences were not significant. Alfadda et al. [39] found median levels of $0.53 \mathrm{ng} / \mathrm{mL}$ for cOC, $1.14 \mathrm{ng} / \mathrm{mL}$ for ucOC and $8.8 \mathrm{ng} /$ $\mathrm{mL}$ for tOC in a group of adults with type 2 diabetes, and they were lower among overweight/obese adults in comparison to what has been reported with normal individuals. In their study, however, tOC was unexpectedly higher than the value obtained by simply summing the two individual fractions. While tOC was measured by ELISA, Alfadda et al. [39] measured cOC and ucOC fractions by enzyme immunoassay (EIA). For these reasons, it is important to take note of the differences among the methods established for measuring osteocalcin, considering that values derived from the RIA appear consistently lower than those from ELISA, the latter of which we used in the current study.

In our study, leptin and ucOC were negatively correlated independent of percent body fat. Leptin, in turn, was a strong positive correlate of insulin resistance and $\beta$-cell function. Despite the effect of leptin on reducing insulin secretion [40], the positive correlation of leptin with HOMA- $\beta$ (an estimate of pancreatic $\beta$-cell function) was expected. In non-diabetic populations - especially among youth - increased insulin secretion precedes insulin resistance [41] and, in the presence of obesity, indicates a risk of developing type-2 diabetes [42]. In contrast to earlier pediatric data, neither tOC nor ucOC correlated with HOMA- $\beta$. Pollock et al. [12] showed positive associations between ucOC and multiple markers of $\beta$-cell responsiveness. However, these findings were evident only in children with pre-diabetes and not those with normal glucose control. The participants in the current study were healthy and absent of any chronic diseases, thus the effect of osteocalcin in modulating insulin secretion may be confined to 
individuals at risk of developing type- 2 diabetes. These data were later supported by Gower et al. [43], but rather in a cohort of overweight and obese adults (mean age $=34.9 \pm 8.3$ years).

Sex-related differences in energy metabolism have been well characterized, with girls being more insulin resistant versus their male counterparts [44-46]. Sex steroids and genetics may partially explain why girls are more inclined than boys to develop disturbances in glucose metabolism [46]. However, as shown by Jeffery et al. [47], the greater adiposity in girls versus boys is also a contributor. In our study, the higher percent body fat in girls was accompanied by higher HOMA- $\beta$ with HOMA-IR being greatest in black girls. Lee et al. [45] reported that female subjects had significantly higher mean HOMA-IR than male subjects $(p=0.02)$. In addition, overweight and obese adolescents had higher HOMA-IR levels compared with normal weight adolescents [45], and no other factor was more influential on HOMA-IR than obesity status. Consistent with these findings, the overweight/obese versus normal weight children in the current study had higher HOMA-IR values, likely due to corresponding elevations in fasting serum insulin in the overweight/obese individuals.

Racial differences in markers of insulin resistance and sensitivity have been found by others $[44,48]$, but not consistently in all studies [45]. We observed that black subjects had higher HOMA- $\beta$, BMI-for-age percentile, serum leptin and tOC than white subjects, and lower ucOC. Black girls also had higher insulin, and consequently HOMA-IR, than the other race by sex groups. A meta-analysis with 74 study cohorts including 3,813 individuals showed that Africans had significantly lower insulin sensitivity and higher insulin response than Caucasian and East Asian subpopulations [48]. This study also found that the stabilization points in the hyperbolic relationship between insulin sensitivity and insulin response in Africans with normal glucose tolerance were located around unstable extreme points in the curve, where a small change in one variable is associated with a large nonlinear change in the other variable. Therefore, among Africans, even a small increase in insulin resistance could lead to a rapid increase in the amount of released insulin required to maintain normal glucose tolerance, which suggests that this particular subpopulation is more vulnerable to the development of type- 2 diabetes. Indeed, the prevalence of type- 2 diabetes is $13.2 \%$ in people of African descent versus 7.6\% in people of non-Hispanic European decent [49].

Our study has some limitations. Because of the crosssectional design, these results do not allow causal inference or temporal associations. Unfortunately, we were unable to collect data on dynamic measures of peripheral glucose metabolism or pancreatic $\beta$-cell function. However, compared to an oral glucose tolerance test, HOMA-IR performed well as a measure of glucose metabolism in obese children and adolescents [50] and has been used previously in pediatric populations of similar age and stage of sexual maturation of the children included in the present study [51]. Our study included healthy children in a narrow range of puberty, thus generalizability to children at all stages of maturation is limited. Additionally, our subjects represented otherwise healthy children and included only a small number (i.e. < 5\%) who presented with a fasting serum glucose within the pre-diabetic range.

\section{Conclusions}

This ancillary cross-sectional analysis shows that leptin concentrations negatively correlated with $\mathrm{ucOC}$ and positively correlated with insulin resistance and $\beta$-cell function estimates in healthy children. However, associations between $\mathrm{OC}$ and markers of energy metabolism were not observed. Whereas our findings do not support the position that $\mathrm{OC}$ plays a direct role in energy metabolism in healthy children, these relationships warrant additional attention within the context of obesity and/or obesityrelated chronic disease specifically through prospective study designs throughout adolescence.

\section{Abbreviations \\ ANOVA: Analysis of variance; BMI: Body mass index; DXA: Dual-energy X-ray absorptiometry; cOC: Carboxylated osteocalcin; ELISA: Enzyme-linked immunosorbant assay; HOMA-IR: Homeostasis Model of Assessment Estimate of Insulin Resistance; HOMA- $\beta$ : Homeostatic Model of Assessment Estimate of $\beta$ Cell Function; LEPR: Leptin receptor; OPG: Osteoprotegerin; RANKL: Receptor activator of nuclear factor KB ligand; RIA: Radioimmunoassay; tOC: Total osteocalcin; ucOC: Undercarboxylated osteocalcin}

\section{Acknowledgements}

The authors would like to thank Anthony Acton for technical support at IUSM; Connie Sullivan, Rachel Limbach, and Marian Hart, nurse coordinators at IUSM; and Jessica Smith, research coordinator at UGA.

\section{Funding}

This study was funded by NIH grants HD057126 (PI: Lewis) and RR025761 (Indiana CTSI, PI: Shekhar). K.V.G. had fellowship support from the São Paulo Research Foundation (FAPESP) 2013/15823-2. K.M.H.G. is supported through $\mathrm{NIH} \mathrm{K01} \mathrm{DK102864.} \mathrm{The} \mathrm{funding} \mathrm{sources} \mathrm{had} \mathrm{no} \mathrm{involvement} \mathrm{in} \mathrm{the} \mathrm{preparation}$ of the manuscript.

\section{Availability of data and materials \\ The datasets used and/or analyzed during the current study are available from} the corresponding author on reasonable request with approval of the PI.

\section{Authors' contributions}

KVG, BRM, CMW, LAM, KMHG, LDM, GPM, were responsible for development of the research question and approach for this secondary analysis. Statistical analyses were performed by KVG, LDM, and GPM. All authors participated in data interpretation. KVG drafted the manuscript. All authors contributed to editing the manuscript and approved its final version.

Competing interests

The authors declare that they have no competing interests.

Consent for publication

Not applicable. 


\section{Ethics approval and consent to participate}

This study was approved by the Institutional Review Boards for Human Subjects at Purdue University, the University of Georgia, and Indiana University School of Medicine. All participants and their parents or legal guardians provided informed assent and consent, respectively.

\section{Author details}

'Department of Nutrition, School of Public Health, University of São Paulo, Avenida Doutor Arnaldo 715, São Paulo CEP 01246-904, Brazil. ${ }^{2}$ Department of Foods and Nutrition, University of Georgia, 305 Sanford Dr, Athens, GA 30602, USA. ${ }^{3}$ Department of Nutrition Science, Purdue University, 700 W. State Street, West Lafayette, IN 47907, USA. ${ }^{4}$ Department of Statistics, Purdue University, 150 N. University Street, West Lafayette, IN 47907, USA.

${ }^{5}$ Department of Medicine, Indiana University School of Medicine, 545 Barnhill Dr, Indianapolis, IN 46202, USA.

Received: 5 November 2016 Accepted: 14 February 2017 Published online: 07 March 2017

\section{References}

1. Ducy P, Amling M, Takeda S, Priemel M, Schilling AF, Beil FT, Shen J, Vinson C, Rueger JM, Karsenty G. Leptin inhibits bone formation through a hypothalamic relay: a central control of bone mass. Cell. 2000;100:197-207.

2. Hinoi $\mathrm{E}$, Gao N, Jung DY, Yadav V, Yoshizawa T, Myers Jr MG, Chua Jr SC Kim JK, Kaestner KH, Karsenty G. The sympathetic tone mediates leptin's inhibition of insulin secretion by modulating osteocalcin bioactivity. J Cell Biol. 2008;183:1235-42.

3. Lee NK, Sowa H, Hinoi E, Ferron M, Ahn JD, Confraveux C, Dacquin R, Mee PJ, McKee MD, Jung DY, Zhang Z, Kim JK, Mauvais-Jarvis F, Ducy P, Karsenty G. Endocrine regulation of energy metabolism by the skeleton. Cell. 2007;130: 456-69.

4. Ferron M, Hinoi E, Karsenty G, Ducy P. Osteocalcin differentially regulates beta cell and adipocyte gene expression and affects the development of metabolic diseases in wild-type mice. Proc Natl Acad Sci U S A. 2008;105: 5266-70.

5. Lecka-Czernik B, Rosen CJ. Energy excess, glucose utilization, and skeletal remodeling: New insights. J Bone Miner Res. 2015;30(8):1356-61.

6. Lecka-Czernik B, Rosen CJ. Skeletal integration of energy homeostasis: translational implications. Bone. 2016;82:35-41.

7. Lombardi G, Sanchis-Gomar F, Perego S, Sansoni V, Banfi G. Implications of exercise-induced adipo-myokines in bone metabolism. Endocrine. 2016; 54(2):284-305.

8. Glass NA, Torner JC, Letuchy EM, Burns TL, Janz KF, Eichenberger Gilmore JM, Schlechte JA, Levy SM. The relationship between greater prepubertal adiposity, subsequent age of maturation, and bone strength during adolescence. J Bone Miner Res. 2016;31(7):1455-65.

9. Pollock NK, Laing EM, Baile CA, Hamrick MW, Hall DB, Lewis RD. Is adiposity advantageous for bone strength? a peripheral quantitative computed tomography study in late adolescent females. Am J Clin Nutr. 2007;86(5):1530-8.

10. Sayers A, Lawlor DA, Sattar N, Tobias JH. The association between insulin levels and cortical bone: findings from a cross-sectional analysis of pQCT parameters in adolescents. J Bone Miner Res. 2012;27(3):610-8.

11. Dimitri P, Bishop N, Walsh JS, Eastell R. Obesity is a risk factor for fracture in children but is protective against fracture in adults: a paradox. Bone. 2012; 50(2):457-66.

12. Pollock NK, Bernard PJ, Gower BA, Gundberg CM, Wenger K, Misra S, Bassali RW, Davis CL. Lower uncarboxylated osteocalcin concentrations in children with prediabetes is associated with beta-cell function. J Clin Endocrinol Metab. 2011;96(7):E1092-1099.

13. Motyl K, Rosen CJ. Understanding leptin-dependent regulation of skeletal homeostasis. Biochimie. 2012;94(10):2089-96.

14. Takeda S, Karsenty G. Molecular bases of the sympathetic regulation of bone mass. Bone. 2008:42:837-40.

15. Thomas T, Gori F, Khosla S, Jensen MD, Burguera B, Riggs BL. Leptin acts on human marrow stromal cells to enhance differentiation to osteoblasts and to inhibit differentiation to adipocytes. Endocrinology. 1999;140(4):1630-8.

16. Lombardi G, Perego S, Luzi L, Banfi G. A four-season molecule: osteocalcin Updates in its physiological roles. Endocrine. 2015;48(2):394-404.

17. Karsenty G, Olson EN. Bone and muscle endocrine functions: unexpected paradigms of inter-organ communication. Cell. 2016;164(6):1248-56.
18. Abseyi N, Siklar Z, Berberoglu M, Hacihamdioglu B, Savas Erdeve S, Oçal G. Relationships between osteocalcin, glucose metabolism, and adiponectin in obese children: is there crosstalk between bone tissue and glucose metabolism? J Clin Res Pediatr Endocrinol. 2012;4(4):182-8.

19. Lu C, Ivaska KK, Alen M, Wang Q, Tormakangas T, Xu L, Wiklund P, Mikkola TM, Pekkala S, Tian H, Väänänen HK, Cheng S. Serum osteocalcin is not associated with glucose but is inversely associated with leptin across generations of nondiabetic women. J Clin Endocrinol Metab. 2012;97(11): 4106-14.

20. Kindblom JM, Ohlsson C, Ljunggren O, Karlsson MK, Tivesten A, Smith U, Mellström D. Plasma osteocalcin is inversely related to fat mass and plasma glucose in elderly swedish men. J Bone Miner Res. 2009;24:785-91.

21. Pittas AG, Harris SS, Eliades M, Stark P, Dawson-Hunghes B. Association between serum osteocalcin and markers of metabolic phenotype. J Clin Endocrinol Metab. 2009;94:827-32.

22. Zhou M, Ma X, Li H, Pan X, Tang J, Gao Y, Hou X, Lu H, Bao Y, Jia W. Serum osteocalcin concentrations in relation to glucose and lipid metabolism in Chinese individuals. Eur J Endocrinol. 2009;161:723-9.

23. Reinehr T, Roth CL. A new link between skeleton, obesity and insulin resistance: relationships between osteocalcin, leptin and insulin resistance in obese children before and after weight loss. Int J Obes (Lond). 2010; 34(5):852-8.

24. Sansoni V, Vernillo G, Perego S, Barbuti A, Merati G, Schena F, La Torre A, Banfi G, Lombardi G. Bone turnover response is linked to both acute and established metabolic changes in ultra-marathon runners. Endocrine. 2016. [Epub ahead of print]

25. Lombardi G, Lanteri P, Graziani R, Colombini A, Banfi G, Corsetti R. Bone and energy metabolism parameters in professional cyclists during the giro d'Italia 3-weeks stage race. PLoS One. 2012;7(7):e42077.

26. Lewis RD, Laing EM, Hill Gallant KM, Hall DB, McCabe GP, Hausman DB, Martin BR, Warden SJ, Peacock M, Weaver CM. A randomized trial of vitamin D3 supplementation in children: dose-response effects on vitamin D metabolites and calcium absorption. J Clin Endocrinol Metab. 2013;98:4816-25.

27. Kuczmarski RJ, Ogden CL, Grummer-Strawn LM, Flegal KM, Guo SS, Wei R, Mei Z, Curtin LR, Roche AF, Johnson CL. CDC growth charts: United States. Adv Data. 2000;314:1-27.

28. Williams DP, Going SB, Lohman TG, Harsha DW, Srinivasan SR, Webber LS, Berenson GS. Body fatness and risk for elevated blood pressure, total cholesterol, and serum lipoprotein ratios in children and adolescents. Am J Public Health. 1992;82(3):358-63.

29. Going SB, Lohman TG, Eisenmann JC. Body composition assessments. In: Plowman SA, Meredith MD, editors. Fitnessgram/activitygram reference guide. 4th ed. Dallas: The Cooper Institute; 2013. p. 7-9. http://www. cooperinstitute.org/reference-guide. Accessed 20 Oct 2016.

30. Pramojanee SN, Phimphilai M, Chattipakorn N, Chattipakorn SC. Possible roles of insulin signaling in osteoblasts. Endocr Res. 2014;39(4):144-51.

31. Karsenty G, Ferron M. The contribution of bone to whole organism physiology. Nature. 2012;481:314-20.

32. Ferron M, Wei J, Yoshizawa T, Del Fattore A, DePinho RA, Teti A, Ducy P, Karsenty G. Insulin signaling in osteoblasts integrates bone remodeling and energy metabolism. Cell. 2010;142(2):296-308.

33. Takaya J, Tanabe Y, Kuroyanagi Y, Kaneko K. Decreased undercarboxylated osteocalcin in children with type 2 diabetes mellitus. J Pediatr Endocrinol Metab. 2016;29(8):879-84.

34. Tubic B, Magnusson P, Mårild S, Leu M, Schwetz V, Sioen I, Herrmann D, Obermayer-Pietsch B, Lissner L. Swolin-eide D; IDEFICS consortium. Different osteocalcin forms, markers of metabolic syndrome and anthropometric measures in children within the IDEFICS cohort. Bone. 2016;84:230-6.

35. Rosato MT, Schneider SH, Shapses SA. Bone turnover and insulin-like growth factor I levels increase after improved glycemic control in noninsulin-dependent diabetes mellitus. Calcif Tissue Int. 1998;63(2):107-11.

36. Okazaki R, Totsuka Y, Hamano K, Ajima M, Miura M, Hirota Y, Hata K, Fukumoto S, Matsumoto T. Metabolic improvement of poorly controlled noninsulin-dependent diabetes mellitus decreases bone turnover. J Clin Endocrinol Metab. 1997;82(9):2915-20.

37. Van Summeren M, Braam L, Noirt F, Kuis W, Vermeer C. Pronounced elevation of undercarboxylated osteocalcin in healthy children. Pediatr Res. 2007:61:366-70

38. Rochefort GY, Rocher E, Aveline PC, Garnero P, Bab I, Chappard C, Jaffré C, Benhamou CL. Osteocalcin-insulin relationship in obese children: a role for the skeleton in energy metabolism. Clin Endocrinol (Oxf). 2011;75(2):265-70. 
39. Alfadda AA, Masood A, Shaik SA, Dekhil H, Goran M. Association between osteocalcin, metabolic syndrome, and cardiovascular risk factors: role of total and undercarboxylated osteocalcin in patients with type 2 diabetes. Int J Endocrinol. 2013;2013:197519.

40. Kieffer TJ, Heller RS, Leech CA, Holz GG, Habener JF. Leptin suppression of insulin secretion by the activation of ATP-sensitive K+ channels in pancreatic beta-cells. Diabetes. 1997;46(6):1087-93.

41. Cali AM, Caprio S. Prediabetes and type 2 diabetes in youth: an emerging epidemic disease? Curr OpinEndocrinol Diabetes Obes. 2008;15(2):123-7.

42. Steinberger J, Daniels SR, American Heart Association Atherosclerosis, Hypertension, and Obesity in the Young Committee (Council on Cardiovascular Disease in the Young); American Heart Association Diabetes Committee (Council on Nutrition, Physical Activity, and Metabolism). Obesity, insulin resistance, diabetes, and cardiovascular risk in children: an american heart association scientific statement from the atherosclerosis, hypertension, and obesity in the young committee (council on cardiovascular disease in the young) and the diabetes committee (council on nutrition, physical activity, and metabolism). Circulation. 2003;107(10):1448-53.

43. Gower BA, Pollock NK, Casazza K, Clemens TL, Goree LL, Granger WM. Associations of total and undercarboxylated osteocalcin with peripheral and hepatic insulin sensitivity and $\beta$-cell function in overweight adults. J Clin Endocrinol Metab. 2013;98(7):E1173-80.

44. Arslanian S, Suprasongsin C. Differences in the in vivo insulin secretion and sensitivity of healthy black versus white adolescents. J Pediatr. 1996;129: 440-3.

45. Lee JM, Okumura MJ, Davis MM, Herman WH, Gurney JG. Prevalence and determinants of insulin resistance among U.S. Adolescents: a populationbased study. Diabetes Care. 2006;29(11):2427-32.

46. Murphy MJ, Metcalf BS, Voss LD, Jeffery AN, Kirkby J, Mallam KM, Wilkin TJ. EarlyBird study (EarlyBird 6). girls at five are intrinsically more insulin resistant than boys: the programming hypotheses revisited - the EarlyBird study (EarlyBird study 6). Pediatrics. 2004;113(1):82-6.

47. Jeffery AN, Metcalf BS, Hosking J, Streeter AJ, Voss LD, Wilkin TJ. Age before stage: insulin resistance rises before the onset of puberty: a 9-year longitudinal study (EarlyBird 26). Diabetes Care. 2012;35(3):536-41.

48. Kodama K, Tojjar D, Yamada S, Toda K, Patel CJ, Butte AJ. Ethnic differences in the relationship between insulin sensitivity and insulin response: a systematic review and meta-analysis. Diabetes Care. 2013;36(6):1789-96.

49. Centers for Disease Control and Prevention. National diabetes statistics report: estimates of diabetes and its burden in the united states, 2014. Atlanta: US Department of Health and Human Services; 2014.

50. Keskin M, Kurtoglu S, Kendirci M, Atabek ME, Yazici C. Homeostasis model assessment is more reliable than the fasting glucose/insulin ratio and quantitative insulin sensitivity check index for assessing insulin resistance among obese children and adolescents. Pediatrics. 2005;115(4):e500-503.

51. Kindler JM, Pollock NK, Laing EM, Jenkins NT, Oshri A, Isales C, Hamrick M, Lewis RD. Insulin resistance negatively influences the muscle-dependent IGF-1-bone mass relationship in premenarcheal girls. J Clin Endocrinol Metab. 2016;101(1):199-205.

\section{Submit your next manuscript to BioMed Central and we will help you at every step:}

- We accept pre-submission inquiries

- Our selector tool helps you to find the most relevant journal

- We provide round the clock customer support

- Convenient online submission

- Thorough peer review

- Inclusion in PubMed and all major indexing services

- Maximum visibility for your research

Submit your manuscript at www.biomedcentral.com/submit 